\title{
Early Detection of Externalizing Problems in Preschool Children According to Their Teachers
}

\author{
Doni Eleni, Artemis Giotsa \\ University of Ioannina, Ioannina, Greece
}

\begin{abstract}
The purpose of this research, which was carried out for the first time in Greece, is to focus on the early detection of preschool children's externalizing problems, according to their teachers' perceptions. Seventy seven preschool teachers $(N=77)$ of 77 half-day and all-day preschool classes from the thirteen regions of Greece, completed: (a) the "Caregiver-Teacher Report Form (C-TRF) for ages 1 1/2 -5" of Achenbach (Achenbach \& Rescorla, 2009) and (b) the "Demographic Questionnaire" (Doni, 2015), considering 1,234 mixed gender (617 boys and 617 girls) children 4-6 years of age. Preschool teachers detected externalizing problems in $11.8 \%$ of their students, of whom $3.0 \%$ were included in the borderline range and $8.8 \%$ in the clinical range. Attention problems were detected in $7.0 \%$ of the children and aggressive behaviour in 5.6\% of them. Statistical analysis showed that preschool teachers detected more externalizing problems in boys and children who attend all-day kindergartens than in girls and children who attend half-day kindergartens. Moreover, attention problems and aggressive behaviour seem to be detected less frequently in classrooms with a large number of students. These results could be used as a reference point for future studies on behavioural difficulties in preschool children.
\end{abstract}

Keywords: preschool teachers' perceptions, early detection, students' externalizing problems, C-TRF of Achenbach

\section{Introduction}

Contemporary epidemiological data show that one in four preschool children deal with some type of behavioral difficulty (Egger \& Angold, 2006). The early appearance of externalizing problems is seen as a result of the child's interactions with the environment (family, school, society), which influences and transforms the idiosyncratic characteristics of the child (Sameroff, 1995) and it is an adequate predictor of the development of externalizing problems in adolescence and adulthood (Campbell \& Ewing, 1990; Egeland, Kalkoske, Gottesman, \& Erickson, 1990; Richman, Stevenson, \& Graham, 1982). Early evaluation of children's behavior, in order to detect possible difficulties, seems to contribute to the long-term avoidance of academic, social, emotional, and behavioral problems (Bornstein, Hahn, \& Haynes, 2010; Feeney-Kettler, Kratochwill, Kaiser, Hemmeter, \& Kettler, 2010; McCabe \& Altamura, 2011). For this reason, preschool age is considered as the best time for an early detection of externalizing problems as well as a period for potential intervention, in order to deal with them, before these difficulties consolidate and lead to serious disorders in the future (Cole, Luby, \& Sullivan, 2008).

Doni Eleni, Ph.D., University Scholar, Department of Early Childhood Education, University of Ioannina.

Artemis Giotsa, Ph.D., Associate Professor of Social Psychology, Director of the Psychology Laboratory, Department of Early Childhood Education, University of Ioannina. 


\section{Externalizing Problems}

According to Achenbach and Rescorla (2009), externalizing problems include attention problems and aggressive behavior. Longitudinal studies confirm that preschool children's externalizing problems show stability and continuity over childhood, in $23 \%$ to $61 \%$ of the cases (Achenbach, Edelbrock, \& Howell, 1987; Bosquet \& Egeland, 2006; Fuchs, Klein, Otto, \& von Klitzing, 2013; Keenan, Shaw, Delliquadri, Giovannelli, \& Walsh, 1998; Strickl, Dijksterhuis, Bos, Sjoerdsma, van Baaren, \& Nordgren, 2011). If they persist at this age, they can be a predictor of more serious problems in adolescence and adulthood (criminal activity, imprisonment, substance use) (Campbell, Shaw, \& Gilliom, 2000).

In most research boys exhibit externalizing problems more often than girls (Beidel, Turner, \& Morris, 2000; Beyer, Postert, Müller, \& Furniss, 2012; Graves, Blake, \& Kim, 2012; Kazdin, 1995; Manolitsis \& Tafa, 2005; Morgan, Farkas, \& Wu, 2008). However, research on age differences is limited and the picture is rather obscure (Poulou, 2013). The type of school (all-day or half-day preschool) is also a factor linked to externalizing problems exhibited by preschool students, since extended school time may be stressful and exhausting (Emery, Wilmot, \& Murphy, 1998; Mashburn \& Henry, 2004). Finally, it is argued that externalizing problems can be more easily developed in preschool classes with a large number of students (Baker, Davies, \& Stallard, 1985; Smith \& Connolly, 1980).

\section{Attention Problems}

Attention problems is a term used to describe a set of problems associated with deficits in visual-motor, cognitive, and social skills (Breslau \& Chilcoat, 2000; Davis, Burns, Wilkerson, \& Steichen, 2005; Harpin, 2005). The scales which are based on older versions of the Achenbach System of Empirically Based Assessment (ASEBA) have included these problems in the attention problems syndrome (Achenbach, 1966; 1978; Achenbach \& Lewis, 1971), while the scales based on the classification of the Diagnostic and Statistical Manual, 4th Edition [DSM-IV (APA, 1994)] of mental disorders, describe these problems as Attention-Deficit/Hyperactivity Disorder (ADHD) (Achenbach, Becker, Döpfner, Heiervang, Roessner, Steinhausen, \& Rothenberger, 2008).

ADHD is a chronic, diffuse childhood disorder, characterized by developmentally inappropriate levels of activity, impulsivity, low tolerance against frustration, poor behavioural regulation, distractibility and failure to maintain concentration (Cormier, 2008; Modesto-Lowe, Danforth, \& Brooks, 2008; Wilens \& Fusillo, 2007). It is a neurobiological syndrome which owes its appearance to genetic and environmental factors (Brassett-Harknett \& Butler, 2007; Waldman \& Gizer, 2006) and has a high heritability rate (Millichap, 2008). The incidence of ADHD in preschool children is approximately $\%$ (Lavigne et al., 1996) and, according to studies, the disorder is diagnosed more often in boys than girls (Barkley, 2006. Huss, Poustka, Lehmkuhl, \& Lehmkuhl, 2008). Nevertheless, research on gender differences suggests that ADHD is an underdiagnosed disorder in girls, mainly due to dissimilarities in the expression of symptoms between boys and girls (Biederman, Lopez, Boeliner, \& Chandler, 2002; Quinn, 2008).

\section{Aggressive Behaviour}

Aggressive behaviour relates to "an action aimed to cause pain, trauma, damage and stress to the other" (Paraskevopoulos, 1985, p. 118). It can be manifested in various ways, such as "physical, verbal, emotional, or not affective aggression and may also be targeted towards a person or be a random act" (Naylor, 2011, p. 64). 
Crick and Dodge (1996) and Dodge (2000) tried to outline the profile of aggressive preschool and school age children through a series of studies. The results revealed characteristics such as immature thinking, egocentricity, language deficiencies, failure to internalize rules and control impulse, as well as severe mental conflicts. Another important research finding is the low esteem of aggressive children (Carney \& Merrell, 2001) or, conversely, the excessive self-esteem that does not correspond to reality (Baumeister, Smart, \& Boden, 1996).

Contemporary research confirms that boys exhibit higher levels of aggression than girls (Hulle, Lemery-Chalfant, \& Goldsmith, 2007; Wichstrom, Berg-Nielsen, Angold, Egger, Solheim, \& Sveen, 2011). Specifically, boys often exhibit physical violence, regardless of their age, while girls aim to cause mainly emotional and not physical trauma (Hodges \& Perry, 1999; Murray-Close, Ostrov, \& Crick, 2007). According to Cole, Teti, and Zahn-Waxler (2003), social expectations as well as common rearing practices may explain why boys exhibit aggressive behaviour more often than girls. They argue that society is more tolerant of boys' aggressive behaviour, while girls are expected to have the role of a peacemaker.

\section{Preschool Teachers' Perceptions of Externalizing Problems}

Preschool teachers' perceptions of the externalizing problems exhibited by their students are likely to be influenced by personal constructs and experiences of the teachers and the social framework in which they act (Sakellariou \& Rentzou, 2012). Therefore these perceptions may be rather subjective, as it occurs by several studies investigating the attitudes of preschool teachers on this issue (Kleftaras \& Didaskalou, 2006; Liljequist \& Renk, 2007; Poulou, 2013; Poulou \& Norwich, 2000). In general, preschool teachers often state that the externalizing problems of their students are too demanding and difficult to deal with (Nutbrown \& Clough, 2004). According to Poulou and Norwich (2000), teachers recognize the importance of factors, associated with them and the school context, which may be responsible for externalizing problems in students. However, Ho's bicultural research (2004) showed that the majority of Australians and Chinese teachers attribute the problematic behavior of children to factors related to the child and not themselves. Research on the relationship between the teachers' age and their beliefs on what causes externalizing problems in students, indicate that young and old teachers ascribe, more often than middle-aged teachers, these problems exclusively to strict or lax rearing practices used by parents (Kleftaras \& Didaskalou, 2006).

\section{Early Detection}

Early detection and early identification of externalizing problems help to understand and address them through the design and implementation of direct and effective interventions (Ashford, Smit, Van Lier, Cuijpers, \& Koot, 2008; Farrington, 2005). Walker, Colvin, and Ramsey (1995) argue that these interventions usually become less effective, once these problems are confronted at the end of primary school years. Additionally, Richman, Stevenson, and Graham (1982) found that $63 \%$ of the children who had developed behavioral problems at the age of three, continued to exhibit these problems at the age of four. Similarly, $62 \%$ of the same children experienced these problems at the age of eight.

Early detection which leads to intervention programs or organized structures, may significantly restrain the development and consolidation of such difficulties that, in turn, can cause school failure (Albers, Kratochwill, \& Glover, 2007). If detection takes place in early childhood then the cost is lower and the interventions needed might be less lengthy and more sustainable. 


\section{Main Research Purpose and Specific Objectives}

The main purpose of our research is to focus on the early detection of preschool children's externalizing problems, according to their teachers' perceptions. Specific objectives of our research were to investigate the factors influencing the detection of externalizing problems by preschool teachers. These factors are related to:

(1) the specific characteristics of their students (gender, age); and

(2) the characteristics of the school unit (type of school, number of children in the classroom).

\section{Research Hypothesis}

Based on the theoretical framework and the main objective of our research, we formulated our research hypotheses as follows:

Hypothesis 1. The classification of students to normal, borderline and clinical range (see below), for the separate syndromes (attention problems, aggressive behaviour) and externalizing problems depends on the gender.

Hypothesis 2. The classification of students to normal, borderline, and clinical range, for the separate syndromes (attention problems, aggressive behaviour) and externalizing problems, depends on their age (4-5, 5-6 years old).

Hypothesis 3. The classification of students to normal, borderline, and clinical range, for the separate syndromes (attention problems, aggressive behaviour) and externalizing problems, depends on the type of school (half-day, all-day).

Hypothesis 4. The classification of students to normal, borderline, and clinical range, for the separate syndromes (attention problems, aggressive behaviour) and externalizing problems, depends on the total number of children in the classroom.

\section{Methodology}

\section{Sample and Design}

The sampling method selected for the particular sample was random sampling in groups or "blocks" (cluster sampling) (Paraskevopoulos, 1993; Tomaras, 2005). This method was considered appropriate because it is used when the role of geography is important (Tomaras, 2005). In this study, the geographical coverage included all the thirteenth regions of Greece. The population consisted of all preschool teachers that worked in half-day and all-day preschool classes (Hellenic Statistical Authority, 2012). On a first level we selected all the thirteen (13) geographical regions of Greece and, on a second level, we randomly selected seventy seven (77) preschool teachers of seventy seven (77) half-day and all-day preschool classes from all the regions. Preschool teachers, after they had been informed for the purpose of the research, completed: (a) C-TRF (Achenbach \& Rescorla, 2009) for children aged 4-6 years ${ }^{1}$, who attended preschool (half-day and all-day), during the academic year 2011-2012 and (b) a "Demographic Questionnaire" (Doni, 2015). These questionnaires were completed after class. After they had completed the questionnaires, they sent them back via post (pre-paid envelope).

\footnotetext{
${ }^{1}$ Collecting data from children aged 5-6 years is allowed, because the age deviation from the norms of FAN-B is not significant (Achenbach \& Rescorla, 2009, https://bib.aseba.org). Moreover, no child in the sample was older than 6 years of age.
} 


\section{Participants}

Seventy seven (77) preschool teachers of 77 half-day and all-day preschool classes (Table 1), from the 13 regions of Greece, completed questionnaires considering 1,234 mixed gender (617 boys and 617 girls) preschoolers 4-6 years of age $(\mathrm{M}=5.65, \mathrm{sd}=0.64)($ Table 2$)$.

Table 1

Type of School

\begin{tabular}{llllll}
\hline & & Number of schools & Percentage \% & Number of students & Percentage \% \\
\hline \multirow{2}{*}{ Type of school } & All-day classes & 52 & 67.5 & 843 & 68.2 \\
& Half-day classes & 25 & 32.5 & 390 & 31.8 \\
& Total & 77 & 100 & 1234 & 100 \\
\hline
\end{tabular}

Table 2

Gender and Age Distribution of Students

\begin{tabular}{llll}
\hline & & Number of students & Percentage \% \\
\hline \multirow{2}{*}{ Gender } & Boys & 617 & 50.0 \\
\multirow{2}{*}{ Total } & Girls & 617 & 50.0 \\
& & 1,234 & 100 \\
Age & $4-5$ years & 437 & 35.6 \\
Total & $5-6$ & 797 & 64.4 \\
\hline
\end{tabular}

\section{Instrumentation}

(A) "Caregiver-Teacher Report Form (C-TRF) for ages 11/2 -5", based on the Achenbach System of Empirically Based Assessment (ASEBA) (Achenbach \& Rescorla, 2009). At the beginning, C-TRF has demographic questions followed by 97 closed-ended questions which reflect the opinions of educators (preschool teachers, childminders or people who take care of children of this age) about internalizing and externalizing problems. Finally, it includes three open-ended questions which are not scored. C-TRF enables a quality assessment of children, classifying boys separately from girls, through cutpoints, to those who belong to the normal range and those who belong to the clinical range. Between normal and clinical ranges, there is one called borderline range. The borderline range indicates that the rating of the child, to one or more syndrome scales, is high enough to create concern about providing the child with professional help, however, it does not deviate as much as a score that is in the clinical range (Achenbach \& Rescorla, 2009, pp. 89-112). C-TRF has been "weighed and translated into more than 60 different languages" (Achenbach \& Rescorla, 2009, p. 13), while its scientific documentation has been recorded, until now, in more than 8,610 scientific articles (ASEBA, https://bib.aseba.org, 2014). C-TRF's scales are harmonized with the diagnostic categories of DSM-IV (Achenbach \& Rescorla, 2009; APA, 1994). For the present study we used the Greek version of C-TRF which was adjusted, validated and weighted in Greek by Ioannis Tsaousis in 2003 (Achenbach \& Rescorla, 2009). Filling in this form does not require any special training, since the instructions are clear and helpful, so that teachers can perform the assessment quickly and easily.

(B) The "Demographic questionnaire" (Doni, 2015). This questionnaire was designed for the purposes of the present research.It is not commercially available and consists of 11 closed-ended and open-ended questions 
that refer to demographic data of preschool teachers (e.g. gender, age, academic level) as well as information on the type of school (half-day, all-day) and the number of students in the classroom (Doni, 2015).

\section{Method of Statistical Analysis}

The classification of children in the clinical, borderline normal range for attention problems, aggressive behaviour and externalizing problems or syndromes group was correlated with the categorical variables which were recorded using the Pearson Chi Square criterion and in cases where the conditions were not met, the Fisher's Exact test. For the correlation with continuous sample measurements, we carried out the necessary normality tests with QQ plots and the Shapiro Wilk criterion. We used one-way Analysis of Variance (ANOVA) or the Kruskal Wallis criterion and then multiple comparisons with the Bonferroni or Dunnets criterion respectively, depending on the fulfillment of conditions. Results were analyzed with the use of multinomial logistic regression models (Garson \& Anderson, 1982). In these models, the different syndromes and the externalizing problems were defined as dependent variables, by classifying children into normal, borderline, and clinical range. The particular characteristics of the children [gender, age (4-5 and 5-6 years old)], the type of school (half-day, all-day) and the number of students in the classroom were defined as independent variables.

\section{Results}

As shown in Table 3, the overall rate of externalizing problems, exhibited by the students was $11.8 \%$. Of them, 3.0\% were included in the borderline range and $8.8 \%$ in the clinical range. Regarding the separate syndromes, $7.0 \%$ of the children experienced attention problems, $4.8 \%$ of whom were included in the borderline range and $2.2 \%$ in the clinical range. Aggressive behaviour was experienced by $5.6 \%$ of the children, of whom, $4.1 \%$ were found at the borderline range and $1.5 \%$ at the clinical range. Table 4 summarizes the means and ranges of the sample's scores of attention problems and aggressive behaviour.

Statistically significant differences (Table 5) were observed in the distribution of normal, borderline and clinical cases, for externalizing problems in relation to: (a) children's gender, $\chi^{2}=18,75, p=0.000$ and (b) the type of school, $\chi^{2}=7.48, p=0.024$.

Statistically significant differences were also found in the distribution of normal, borderline, and clinical cases for both attention problems (Table 6), $\chi^{2}=6.2, p=0.045$ and aggressive behaviour (Table 7), $\chi^{2}=6.88, p$ $=0.032$, in relation to the total number of children in the classroom.

Table 3

Rates for Attention Problems, Aggressive Behavior and Externalizing Problems

\begin{tabular}{llll}
\hline & & Number of students & $\begin{array}{l}\text { Percentage } \\
\%\end{array}$ \\
\hline \multirow{3}{*}{ Attention problems } & Normal & 1,148 & 93.0 \\
& Borderline & 59 & 4.8 \\
& Clinical & 27 & 2.2 \\
\multirow{3}{*}{ Aggressive behavior } & Normal & 1,165 & 94.4 \\
& Borderline & 50 & 4.1 \\
& Clinical & 19 & 1.5 \\
Externalizing problems & Normal & 1,089 & 88.2 \\
& Borderline & 37 & 3.0 \\
& Clinical & 108 & 8.8 \\
\hline
\end{tabular}


Table 4

Means and Ranges of the Sample's Scores of Attention Problems, Aggressive Behaviour and Externalizing Problems

\begin{tabular}{lllll}
\hline \multirow{2}{*}{ Mean } & & \multicolumn{3}{c}{ Possible range according to Achenbach } \\
\cline { 3 - 5 } & & Normal & Borderline & Clinical \\
\hline Attention problems & 1.99 & $0-8$ & $9-14$ & $15-18$ \\
Aggressive behaviour & 4.97 & $0-25$ & $26-34$ & $35-50$ \\
Externalizing problems & 3.48 & $0-18$ & $19-22$ & $23-63$ \\
\hline
\end{tabular}

Table 5

Statistical Correlations of Externalizing Problems

\begin{tabular}{llllc}
\hline & & \multicolumn{2}{c}{ Likelihood ratio tests } \\
\hline Effect & $\begin{array}{l}-2 \text { Log } \\
\text { (Likelihood of reduced model) }\end{array}$ & Chi-quare & Df & Sig. \\
\hline Intercept & $579.955^{\text {a }}$ & 0.000 & 0 & $0.000^{*}$ \\
Children's gender & 598.700 & 18.746 & 2 & 0.972 \\
Children's age & 580.012 & 0.057 & 2 & $0.024^{*}$ \\
Type of school & 587.439 & 7.484 & 2 & 0.225 \\
Total number of children in classroom & 582.939 & 2.984 & 2 & \\
\hline
\end{tabular}

Note. Nagelkerke's Pseudo R Square for the model: 0.164.

Table 6

Statistical Correlations of Attention Problems

\begin{tabular}{llllc}
\hline & & \multicolumn{2}{c}{ Likelihood ratio tests } \\
\hline Effect & $\begin{array}{l}\text { 2 Log } \\
\text { (Likelihood of reduced model) }\end{array}$ & Chi-quare & Df & Sig. \\
\hline Intercept & $437.289^{\mathrm{a}}$ & 0.000 & 0 & 0.077 \\
Children's gender & 442.417 & 5.128 & 2 & 0.745 \\
Children's age & 437.877 & 0.588 & 2 & 0.166 \\
Type of school & 440.883 & 3.594 & 2 & $0.045^{*}$ \\
Total number of children in classroom & 443.486 & 6.196 & 2 & \\
\hline
\end{tabular}

Note. Nagelkerke's Pseudo R Square for the model: 0.112.

Table 7

Statistical Correlations of Aggressive Behaviour

\begin{tabular}{llllc}
\hline & & \multicolumn{2}{c}{ Likelihood ratio tests } \\
\hline Effect & $\begin{array}{l}-2 \text { Log } \\
\text { (Likelihood of reduced model) }\end{array}$ & Chi-quare & Df & Sig. \\
\hline Intercept & $346.731^{\text {a }}$ & 0.000 & 0 & 0.600 \\
Children's gender & 347.753 & 1.022 & 2 & 0.170 \\
Children's age & 350.280 & 3.550 & 2 & 0.058 \\
Type of school & 352.409 & 5.679 & 2 & $0.032^{*}$ \\
Total number of children in the classroom & 353.612 & 6.882 & 2 & \\
\hline
\end{tabular}

Note. Nagelkerke's Pseudo R Square for the model: 0.141.

\section{Discussion}

The purpose of this research is to focus on the early detection of preschool children's externalizing problems, according to their teachers' perceptions. As seen from the results, teachers recorded that $88.2 \%$ of 
their children lie in the normal range. These findings agree with the research findings of Berkhout, Dolk, and Goorhuis-Brouwer (as reported by Berkhout, Hoekman, and Goorhuis-Brouwer, 2012) and Berkhout et al. (2012), in which more than $90 \%$ of the children in their sample were included in the normal range.

The prevalence of externalizing problems was found to relate to $11.8 \%$ of the children. And $8.8 \%$ lie in the clinical range, while 3.0\% are included in the borderline range. Our research findings are consistent with Arnold et al. (2006), who report that $10.0 \%$ of the children in their sample have externalizing problems in the clinical range. Harden et al. (2000) found that $23.7 \%$ of the children in their sample exhibit externalizing problems, of which $15.8 \%$ come under the clinical range, while $7.9 \%$ are included in the borderline range. Finally, Feil, Walker, Severson, and Ball (2000) report that $30.0 \%$ of the children who participated in their research have externalizing problems in the borderline range. Despite the variations, these rates are particularly high.

\section{The Effect of Gender}

There are statistically significant differences between gender and externalizing problems $(p=0.000)$. Specifically, $12 \%$ of the boys were found in the clinical range, $3.7 \%$ in the borderline range, and $84.3 \%$ in the normal range. Respectively, $5.5 \%$ of the girls were found in the clinical range, $2.3 \%$ in the borderline range, and $92.2 \%$ in the normal range. Our research findings are consistent with the research of Berkhout et al. (2012) and Furniss, Beyer, and Guggenmos (2006), where boys also exhibited higher rates of externalizing problems. On the other hand, there are studies that have not found significant differences between gender in the incidence of externalizing problems (Bernstein et al., 1996; Gater et al.,1998; Lavigne et al., 1996).

In this study we do not observe any significant gender differences for attention problems $(p=0.077)$. However, in several studies, the incidence of attention problems is significantly higher among boys (Barkley, 2006; Graves et al., 2012; Huss et al., 2008). Studies on gender differences on ADHD indicate that this disorder is underdiagnosed in girls, mainly due to differences in the expression of the disorder between boys and girls (Biederman et al., 2002; Quinn, 2008). Moreover, Sciutto et al. (2004) argue that boys are referred for diagnosis more often than girls, although the levels of functional impairment may be the same.

Statistically non-significant gender difference $(p=0.600)$ were also observed for aggressive behaviour. A number of researchers (Laursen \& Hartup, 1989; Stallard, 1993; Wheeler, 1994) agree with this finding, arguing that that there are no significant gender differences in the frequency of conflicts or the expression of aggressive behaviour. On the other hand, there are research findings (Hulle et al., 2007; Rubin, Burgess, Dwyer, \& Hastings, 2003; Wichstrom et al., 2011) which confirm that boys exhibit higher levels of aggression than girls. At this point, it is important to clarify that the relationship between externalizing problems and gender cannot be considered causal. A number of factors-interactions between children and their parents, teachers and peers, differences in the level of maturity or the level of empathy (Kerr, Lopez, Olson, \& Sameroff, 2004; Renk, 2008) - may interfere and affect this relationship.

\section{The Effect of Children's Age}

Four hundred and thirty seven (437) out of the one thousand two hundred and thirty four (1,234 children) (35.4\%) are 4-5 years old and seven hundred ninety seven (797) (64.6\%) are 5-6 years old. There is no statistically significant difference between the children's age and externalizing problems, attention problems, and aggressive behaviour. The results of this research are consistent with the research findings of Manolitsis and Tafa (2005), who did not observe any differences in the incidence of externalizing problems between 4-5 
year olds and 5-6 years old. However, according to Poulou (2013), research on age differences in child behaviour during preschool years, is quite limited and the picture is rather obscure.

\section{The Type of School (Half-day/All-day)}

There are statistically significant differences for externalizing problems $(p=0.024)$ in relation to the type of school. For externalizing problems, $12.3 \%$ of the children who attended all-day kindergartens, were found in the clinical range, $3.6 \%$ in the borderline range and $84.1 \%$ in the normal range. Of the children who attended half-day kindergartens, $7.1 \%$ were found in the clinical range, $2.7 \%$ in the borderline range, and $90.2 \%$ in the normal range, respectively. Results show that extended school time, has a clearly negative (mainly clinical range), or somewhat negative impact (borderline range) on the social and emotional functioning of the children in our sample. These findings are confirmed by other studies, according to which, the extended school time in kindergartens actually exhausts children (Emery, Wilmot, \& Murphy, 1998), who consequently argue with their teachers and exhibit more externalizing problems, due to stress and frustration caused by the extended time spent at school (Mashburn \& Henry, 2004). A possible explanation is given by several researchers (Alevriadou, Vrinioti, Kiridis, Sivropoulou-Theodosiadou, \& Chrisafidis, 2008; Elicker \& Mathur, 1997; Gliaou-Christodoulou, 2004; Patiniotis, 2005), who argue that extended school does not enhance social and emotional skills in children such as cooperation, mutual support, conflict management, and self-confidence.

\section{The Total Number of Children in the Classroom}

From our results it occurs that, in classes with larger numbers of students, there are more cases of children among the normal range, than among the borderline or clinical range for aggressive behaviour $(p=0.032)$ and attention problems $(p=0.045)$. However, meta-analytic studies suggest that the number of children in the classroom is not substantially related to the incidence of externalizing problems in children (Rutter, 1983). Given that externalizing problems in preschool children are mainly associated with dysfunctional relationships (Henricsson \& Rydell, 2006), the infrequent incidence of such problems in crowded classrooms could possibly be due to the existence of positive interactions among students. Papastamatis (1998) argues that the culture of healthy competition is created more often in classes with a large number of students. Moreover children learn how to regulate and control their behaviour in order to be accepted by peers and imitate behaviours and reactions from a wide range of choices.

Instead, Finn, and Achilles (1990), observe that in small classes there is a better interaction between teachers and students, which allows teachers to have an individual involvement with each student. According to Howes, Phillips, and Whitebook (1992), preschool teachers provide a developmentally more appropriate education in classes with no more than 10 children. These findings seem to be confirmed by the majority of preschool teachers in Greece, who claim - in a research conducted by Papatheodorou and Ramasut (1994) - that behavioural difficulties are more likely to occur in classes with a large number of students.

\section{Conclusion}

Through this study, there has been an effort, for the first time in Greece, to explore, on a national level, whether preschool students exhibit externalizing problems which can be detected by their preschool teachers. The findings show that boys exhibit higher rates of externalizing problems than girls. Moreover, the prevalence of externalizing problems seems to be higher in preschoolers who attended all-day preschool. Finally, aggressive behaviour and attention problems are less frequent in classes with larger numbers of students. 
These results could be used as a reference point and as a point of comparison in future, more specialized studies on the social and emotional functioning of preschool children. Moreover, they could be useful in a future revision of the Greek analytical curriculum for preschool education, which should aim at the behavioural, emotional, and social development of children, among other targets. Finally, we should point out how important is for preschool teachers to be able to use suitable psychometric tools, in order to detect externalizing problems in preschool children and then design the right intervention programmes. C-TRF (Achenbach \& Rescorla, 2009) combines many of the elements that a psychometric tool must have, to ensure comprehensive, accurate, and reliable detection of externalizing problems in preschool children, mainly because it allows the collection and comparison of information from multiple sources.

\section{Limitations_-Suggestions for future research}

While considering methodological implications of the current study, the sampling design and in turn overgeneralization of the findings should be taken into account. Preschool teachers' perceptions on children's externalizing problems carry a large degree of subjectivity, an element which exists almost as a "principle" in several studies which explore the perceptions of preschool teachers on this issue (Kleftaras \& Didaskalou, 2006; Liljequist \& Renk, 2007; Poulou, 2013; Poulou \& Norwich, 2000). In a future research, information for a child may be collected, from parents and other important key persons (e.g. a grandmother or a grandfather), independently or in combination with C-TRF, using a valid and reliable psychometric tool the "Child Behavior Checklist for ages 1 $1 \frac{1}{2}-5$ " (CBCL) of Achenbach, which has been also standardized for Greek populations (Achenbach \& Rescrola, 2009; Rescorla, 2009). Moreover, in a different research caregivers could be included in the sample, in order to avoid the overestimation of parental reports (Carter, Briggs-Gowan, \& Davis, 2004). Future research could also examine the effect of specific variables-factors related to the family, on the incidence of externalizing problems in preschool children, as for example, parents' occupation, family income, family size, parents' age, child's place of residence, and type of family (nuclear, extended, single parent, binuclear). Other factors such as the emotional climate of the family, parental psychopathology, and rearing practices (parenting) are worth exploring. It would be also interesting if researchers examined the effect of variables related to the psychological state of preschool teachers (stress, depression, job burnout), on the way they detect externalizing problems exhibited by their students. Furthermore, the influence of factors associated with neighborhood and community, on the incidence of externalizing problems in children, is rather interesting for future research.

Conflict of interest: The authors have no conflicts of interest to declare.

Informed consent: Informed consent was obtained from all individual participants included in the study.

Ethical approval: All procedures performed in studies involving human participants were in accordance with the ethical standards of the University of Ioannina and the 1964 Helsinki declaration and its later amendments or comparable ethical standards.

This article does not contain any studies with animals performed by any of the authors.

\section{References}

Achenbach, T. M. (1966). The classification of children's psychiatric symptoms: A factor-analytic study. Psychological Monographs, 80(7), 1-37.

Achenbach, T. M. (1978). The child behavior profile: I. Boys aged 6-11. Journal of Consulting and Clinical Psychology, 46(3), 478-488. 
Achenbach, T. M., Becker, A., Döpfner, M., Heiervang, E., Roessner, V., Steinhausen, H., \& Rothenberger, A. (2008). Multicultural assessment of child and adolescent psychopatholgy with ASEBA and SDQ instruments: Research findings, applications, and future directions. Journal of Child Psychology and Psychiatry, 49, 251-275.

Achenbach, T. M., \& Edelbrock, C. S. (1984). Psychopathology of childhood. Annual Review of Psychology, 35, $227-256$.

Achenbach, T. M., Edelbrock, C., \& Howell, C. T. (1987). Empirically based assessment of the behavioral/emotional problems of 2-3-year-old children. Journal of Abnormal Child Psychology, 15, 629-650.

Achenbach, T. M., \& Lewis, M. (1971). A proposed model for clinical research and its application to encopresis and enuresis. Journal of the American Academy of Child Psychiatry, 10(3), 535-554.

Achenbach, T. M., \& Rescorla, L. A. (2000). Manual for the ASEBA preschool forms and profiles. Burlington, VT: University of Vermont, Department of Psychiatry.

Achenbach, T. M., \& Rescorla, L. A. (2009). Manual for ASEBA preschool forms \& profiles (Adaptation—Standardization for the Greek Language: Tsaousis, I.). Athens: Ellinika Grammata [in Greek].

Albers, C. A., Kratochwill, T. R., \& Glover, T. A. (2007). Where are we and where do we go now? Universal screening for enhanced educational and mental health outcomes. Journal of School Psychology, 45, 257-263.

Alevriadou, A., Vrinioti, K., Kiridis, A., Sivropoulou-Theodosiadou, E., \& Chrisafidis, K. (2008). All-day kindergarten guide. Athens: Pataki [in Greek].

American Psychiatric Association (APA). (1994). Diagnostic and statistical manual of mental disorders (DSM-IV). Washington, DC: American Psychiatric Association.

Arnold, D., Brown, S., Meagher, S., Baker, C., Dobbs, J., \& Doctoroff, G. (2006). Preschool-based programs for externalizing problems. Education and Treatment of Children, 29(2), 311-339.

Ashford, J., Smit, F., Van Lier, P. A., Cuijpers, P., \& Koot, H. M. (2008). Early risk indicators of internalizing problems in late childhood: A 9-year longitudinal study. Journal of Child Psychology and Psychiatry, 49(7), 774-780.

Baker, C., Davies, N., \& Stallard, T. (1985). Prevalence of behaviour problems in primary school children in north Wales. British Journal of Special Education, 12(1), 19-21.

Barkley, R. A. (Ed.). (2006). Attention-deficit hyperactivity disorder: A handbook for diagnosis and treatment. New York: Guilford Publications.

Baumeister, R. F., Smart, L., \& Boden, J. M. (1996). Relation of threatened egotism to violence and aggression: The dark side of high self-esteem. Psychological Review, 103(1), 5-33.

Beidel, D. C., Turner, S. M., \& Morris, T. L. (2000). Behavioral treatment of childhood social phobia. Journal of Consulting and Clinical Psychology, 68(6), 1072-1080.

Bennett, P., Elliott, M., \& Peters, D. (2005). Classroom and Family Effects on Children's Social and Behavioral Problems. The Elementary School Journal, 105(5), 461-480.

Berkhout, L., Hoekman, J., \& Goorhuis-Brouwer, S. M. (2012). Psychosocial health of 4-year-old boys and girls, as observed by parents and teachers. European Journal of Developmental Psychology, 9(4), 500-507.

Beyer, T., Postert, C., Müller, J., \& Furniss, T. (2012). Prognosis and continuity of child mental health problems from preschool to primary school: Results of a four-year longitudinal study. Child Psychiatry Hum Dev, 43(4), 533-543.

Bernstein, G. A., Massie, E. D., Thuras, P. D., Perwien, A. R., Borchardt, C. M., \& Crosby, R. D. (1997). Somatic symptoms in anxious-depressed school refusers. Journal of the American Academy of Child \& Adolescent Psychiatry, 36(5), 661-668.

Biederman, J., Lopez, F. A., Boellner, S. W., \& Chandler, M. C. (2002). A randomized, double-blind, placebo-controlled, parallel-group study of SLI381 (Adderall XR) in children with attention-deficit/hyperactivity disorder. Pediatrics, 110, 258-266.

Bornstein, M. H., Hahn, C., \& Haynes, O. M. (2010). Social competence, externalizing and internalizing behavioral adjustment from early childhood through early adolescence: Developmental cascades. Development and Psychopathology, 22(4), 717-735.

Bosquet, M., \& Egeland, B. (2006). The development and maintenance of anxiety symptoms from infancy through adolescence in a longitudinal sample. Development and Psychopathology, 18(2), 517-550.

Brassett-Harknett, A., \& Butler, N. (2007). Attention-deficit/hyperactivity disorder: An overview of the etiology and a review of the literature relating to the correlates and lifecourse outcomes for men and women. Clinical Psychology Review, 27(2), $188-210$

Breslau, N., \& Chilcoat, H. D. (2000). Psychiatric sequelae of low birth weight at 11 years of age. Biological Psychiatry, 47(11), 1005-1011.

Campbell, S. B., \& Ewing, L. (1990). Follow-up of hard to manage preschoolers: Adjustment at age 9 and predictors of continuing symptoms. Journal of Child Psychology and Psychiatry, 31, 871-889. 
Campbell, S., Shaw, D., \& Gilliom, M. (2000). Early externalizing behavior problems: Toddlers and preschoolers at risk for later maladjustment. Development and Psychopathology, 12(3), 467-488.

Carney, A., \& Merrell, K. (2001). Bullying in schools: Perspective on understanding and preventing an international problem. School Psychology International, 22(3), 364-382.

Carter, A. S., Briggs-Gowan, M. J., \& Davis, N. O. (2004). Assessment of young children's social-emotional development and psychopathology: Recent advances and recommendations for practice. Journal of Child Psychology and Psychiatry, 45(1), 109-134.

Cole, P. M., Luby, J., \& Sullivan, M. W. (2008). Emotions and the development of childhood depression: Bridging the gap. Child Development Perspectives, 2(3), 141-148.

Cole, P., Teti, L. O., \& Zahn-Waxler, C. (2003). Mutual emotion regulation and the stability of conduct problems between preschool and early school age. Development and Psychopathology, 15(01), 1-18.

Costello, E., \& Angold, A. (1995). Epidemiology. In J. S. March (Ed.), Anxiety disorders in children and adolescents (pp. 109-124). New York: Guilford.

Cormier, E. (2008). Attention deficit/hyperactivity disorder: a review and update. Journal of Pediatric Nursing, 23(5), 345-357.

Crick, N. R., \& Dodge, K. A. (1996). Social information-processing mechanisms in reactive and proactive aggression. Child Development, 67(3), 993-1002.

Davis, D. W., Burns, B. M., Wilkerson, S. A., \& Steichen, J. J. (2005). Visual perceptual skills in children born with very low birth weights. Journal of Pediatric Health Care, 19(6), 363-368.

Dodge, K. (2000). Conduct disorders. In A. J. Sameroff, M. Lewis, and M. S. Miller (Eds.), Handbook of developmental psychopathology (2nd ed., pp. 447-463). New York: Klewer Academic/ Plenum Publishers.

Doni, E. (2105). Preschool teachers' perceptions on the early detection of emotional and behavioural difficulties in preschool children. A nationwide survey (Doctoral dissertation). School of Education, Department of Early Childhood Education, University of Ioannina, Ioannina [in Greek].

Egeland, B., Kalkoske, M., Gottesman, N., \& Erickson, M. F. (1990). Preschool behavior problems: Stability and factors accounting for change. Journal of Child Psychology and Psychiatry, 31(6), 891-909.

Egger, H., \& Angold, A. (2006). Common emotional and behavioral disorders in preschool children: Presentation, nosology and epidemiology. Journal of Child Psychology and Psychiatry, 47, 313-337.

Eisenberg, N., Cumberland, A., Spinrad, T., Fabes, R., Shepard, St., Reiser, M., et al. (2001). The relations of regulation and emotionality to children's externalizing and internalizing problem behavior. Child Development, 72(4), 1112-1134.

Elicker, J., \& Mathur, S. (1997). What do they do all day? Comprehensive evaluation of a full-day kindergarten. Early Childhood Research Quarterly, 12(4), 459-480.

Emery, H., Wilmot, J., \& Murphy, R. (1998). Consistency in teacher assessment and the impact of SCAA guidance materials at key stage 3 in the non-core subjects: Report to QCA. Nottingham: School of Education, University of Nottingham.

Farringhton, D. P. (2005). Childhood origins of antisocial behavior. Clinical Psychology \& Psychotherapy, 12(3), 177-190.

Feeney-Kettler, K. A., Kratochwill, T. R., Kaiser, A. P., Hemmeter, M. L., \& Kettler, R. J. (2010). Screening young children's risk for mental health problems: A review of four measures. Assessment for Effective Intervention, 35(4), 218-230.

Finn, J., \& Achilles, Ch. (1990). Answers and questions about class size: A statewide experiment. American Educational Research Journal, 27(3), 557-577.

Feil, E. G., Walker, H. M., Severson, H. H., \& Ball, A. (2000). Proactive screening for emotional/behavioral concerns in head start preschools: Promising practices and challenges in applied research. Behavior Disorders, 26(1), 13-25.

Fuchs, S., Klein, A. M., Otto, Y., \& von Klitzing, K. (2013). Prevalence of emotional and behavioral symptoms and their impact on daily life activities in a community sample of 3 to 5-year-old children. Child Psychiatry \& Human Development, 44(4), 493-503.

Furniss, T., Beyer, T., \& Guggenmos, J. (2006). Prevalence of behavioural and emotional problems among six-years-old preschool children. Social Psychiatry and Psychiatric Epidemiology, 41(5), 394-399.

Garson, D., \& Anderson, J. A. (1982). Logistic regression. Handbook of Statistics. New York.

Gater, R., Tansella, M., Korten, A., Tiemens, B. G., Mavreas, V. G., \& Olatawura, M. O. (1998). Sex differences in the prevalence and detection of depressive and anxiety disorders in general health care settings: Report from the World Health Organization collaborative study on psychological problems in general health care. Archives of General Psychiatry, 55(5), 405-413.

Gilliom, M., \& Shaw, D. S. (2004). Codevelopment of externalizing and internalizing problems in early childhood. Development and Psychopathology, 16(2), 313-333. 
Gliaou-Christodoulou, N. (2004). Priorities and innovations for the Kindergarten of the 21st century. In P. Aggelidis and G. Mavroidis (Eds.), Educational innovations for the school of the future. Athens: Typothito [in Greek].

Graves, S., Blake, J., \& Kim, E. (2012). Differences in parent and teacher ratings of preschool problem behavior in a national sample: The significance of gender and SES. Journal of Early Intervention, 34(3), 151-165.

Harden, B. J., Winslow, M. B., Kendziora, K. T., Shahinfar, A., Rubin, K. H., Fox, N. A., et al. (2000). Externalizing problems in head start children: An ecological exploration. Early Education and Development, 11, 357-385.

Harpin, V. A. (2005). The effect of ADHD on the life of an individual, their family, and community from preschool to adult life. Archives of Disease in Childhood, 90, 2-7.

Hellenic Statistical Authority. http://www.statistics.gr/el/home/. Accessed 27 February 2012.

Henricsson, L., \& Rydell, A. M. (2006). Children with behaviour problems: The influence of social competence and social relations on problem stability, school achievement and peer acceptance across the first six years of school. Infant and Child Development, 15(4), 347-366.

Ho, I. T. (2004). A comparison of Australian and Chinese teachers' attributions for student problem behaviors. Educational Psychology, 24(3), 375-391.

Hodges, E. V., \& Perry, D. G. (1999). Personal and interpersonal antecedents and consequences of victimization by peers. Journal of Personality and Social Psychology, 76(4), 677-689.

Howes, C., Phillips, D. A., \& Whitebook, M. (1992). Thresholds of quality: Implications for the social development of children in center-based child care. Child Dev, 63, 449-460.

Hulle, V. C. A., Lemery-Chalfant, K., \& Goldsmith, H. H. (2007). Genetic and environmental influences on socioemotional behavior in toddlers: An initial twin study of the infant toddler social and emotional assessment. Journal of Child Psychology and Psychiatry, 48(10), 1014-1024.

Huss, M., Poustka, F., Lehmkuhl, G., \& Lehmkuhl, U. (2008). No increase in long-term risk for nicotine use disorders after treatment with methylphenidate in children with attention-deficit/hyperactivity disorder (ADHD): Evidence from a non-randomised retrospective study. Journal of Neural Transmission, 115(2), 335-339.

Kazdin, A. E. (1995). Child, parent and family dysfunction as predictors of outcome in cognitive-behavioral treatment of antisocial children. Behaviour Research and Therapy, 33(3), 271-281.

Keenan, K., Shaw, D. S., Delliquadri, E., Giovannelli, J., \& Walsh, B. (1998). Evidence for the continuity of early problem behaviors: Application of a developmental model. Journal of Abnormal Child Psychology, 26, 443-454.

Keenan, K., Shaw, D. S., Walsh, B., Delliquadri, E., \& Giovannelli, J. (1997). DSM-III-R disorders in preschool children from low-income families. Journal of the American Academy of Child and Adolescent Psychiatry, 36, 620-627.

Kerr, D., Lopez, N., Olson, S., \& Sameroff, A. (2004). Parental discipline and externalizing behavior problems in early childhood: The roles of moral regulation and child gender. Journal of Abnormal Child Psychology, 32(4), 369-383.

Kleftaras, G., \& Didaskalou, E. (2006). Incidence and teachers' perceived causation of depression in primary school children in Greece. School Psychology International, 27(3), 296-314.

Laursen, B., \& Hartup, W. (1989). The dynamics of preschool children's conflicts. Merrill Palmer Quarterly, 35(3), $281-297$.

Lavigne, J. V., Gibbons, R. D., Christoffel, K. K., Arend, R., Rosenbaum, D., Binns, H., et al. (1996). Prevalence rates and correlates of psychiatric disorders among preschool children. Journal of the American Academy of Child and Adolescent Psychiatry, 35(2), 204-214.

Liljequist, L., \& Renk, K. (2007). The relationships among teachers' perceptions of student behaviour, teachers' characteristics, and ratings of students' emotional and behavioural problems. Educational Psychology, 27(4), 557-571.

Manolitsis, G., \& Tafa, E. (2005). Checklist for screening behavioural problems in preschool children. Psychology: The Journal of the Hellenic Psychological Society, 12(2), 153-178 [in Greek].

Mashburn, A. J., \& Henry, G. T. (2004). Assessing school readiness: Validity and bias in preschool and kindergarten teachers' ratings. Educational Measurement: Issues and Practice, 23, 16-30.

McCabe, P. C., \& Altamura, M. (2011). Empirically valid strategies to improve social and emotional competence of preschool children. Psychology in the Schools, 48(5), 513-540.

Millichap, J. G. (2008). Etiologic classification of attention-deficit/hyperactivity disorder. Pediatrics, 121(2), 358-365.

Modesto-Lowe, V., Danforth, J. S., \& Brooks, D. (2008). ADHD: Does parenting style matter?. Clinical Pediatrics, 47, 865-872.

Morgan, P., Farkas, G., \& Wu, Q. (2008). Kindergarten predictors of recurring externalizing and internalizing psychopathology in the third and fifth grades. Journal of Emotional and Behavioral Disorders, 17(2), 67-79. 
Murray, C., D., Ostrov, J., \& Crick, N. (2007). A short-term longitudinal study of growth of relational aggression during middle childhood: Associations with gender, friendship intimacy, and internalizing problems. Development and Psychopathology, $19,187-203$

Naylor, J. (2011). Aggression. In S. Goldstein and J. A. Naglieri (Eds.), Encyclopedia of child behavior and development (pp. 64-66). Heidelberg: Springer.

Nottelmann, E. D., \& Jensen, P. S. (1995). Comorbidity of disorders in children and adolescents. In T. Ollendick and R. Prinz (Eds.), Advances in clinical child psychology (pp. 109-155). New York: Plenum Press.

Nutbrown, C., \& Clough, P. (2004). Inclusion in the early years: Conversations with European educators. European Journal of Special Needs Education, 19(3), 311-339.

Papastamatis, A. (1998). Is the teaching of "I think and I write" effective? Pedagogical Review, 28, $37-53$ [in Greek].

Papatheodorou, T., \& Ramasut, A. (1994). Environmental effects on teachers' perceptions of behaviour problems in nursery school children. European Early Childhood Education Research Journal, 2(2), 63-78.

Paraskevopoulos, I. (1985). Developmental psychology. Athens: Author [in Greek].

Paraskevopoulos, I. N. (1993). Applied statistics for behavioral sciences. Athens: Self Publishing [in Greek].

Patiniotis, N. (2005). The full-day nursery school. Athnes:Tipothito [in Greek].

Poulou, M. (2013). Emotional and behavioural difficulties in preschool. Journal of Child and Family Studies, 24(2), 225-236.

Poulou, M., \& Norwich, B. (2000). Teachers' causal attributions, cognitive, emotional and behavioural responses to students with emotional and behavioural difficulties. British Journal of Educational Psychology, 70(4), 559-581.

Quinn, P. O. (2008). Attention-deficit/hyperactivity disorder and its comorbidities in women and girls: an evolving picture. Current Psychiatry Reports, 10(5), 419-423.

Renk, K. (2008). Disorders of conduct in young children: Developmental considerations, diagnoses and other characteristics. Developmental Review, 28(3), 316-341.

Rescorla, L. (2009). Age 17 language and reading outcomes in late-talking toddlers: Support for a dimensional perspective on language delay. Journal of Speech, Language, and Hearing Research, 52(1), 16-30.

Richman, N., Stevenson, J., \& Graham, E. J. (1982). Pre-school to school. A behavioural study. London: Academic Press.

Rubin, K., Burgess, K. B., Dwyer, K. M., \& Hastings, P. (2003). Predicting preschoolers' externalizing behaviors from toddler temperament, conflict, and maternal negativity. Developmental Psychology, 39(1), 164-176.

Rutter, M. (1983). School effects on pupil progress: Research findings and policy implications. Child Development, 54(1), 1-29.

Sakellariou, M., \& Rentzou, K. (2012). Greek pre-service kindergarten teachers' beliefs and intensions about the importance of teacher-child interactions. Early Child Development and Care, 182(1), 123-135.

Sameroff, A. J. (1995). General systems theory and developmental psychopathology. In D. Cicchetti and D. Cohen (Eds.), Developmental psychopathology (Vol. 1, pp. 659-695). New York: Wiley.

Sciutto, M. J., Nolfi, C. J., \& Bluhm, C. (2004). Effects of child gender and symptom type on referrals for ADHD by elementary school teachers. Journal of Emotional and Behavioral Disorders, 12(4), 247-253.

Smith, P. K., \& Connolly, K. J. (1980). The ecology of preschool behaviour. New York: Cambridge University Press.

Stallard, P. (1993). The behaviour of 3-year-old children: Prevalence and parental perception of problem behaviour: A research note. Journal of Child Psychology and Psychiatry, 34(3), 413-421.

Strickl, M., Dijksterhuis, A., Bos, M. W., Sjoerdsma, A., van Baaren, R. B., \& Nordgren, L. F. (2011). A meta-analysis on unconscious thought effects. Social Cognition, 29(6), 738-762.

Tomaras, P. (2005). Applied marketing research. Athens: Self Publishing [in Greek].

Veniakaki, A. (2009). Literacy difficulties and emotional and behavioural problems (Doctoral dissertation). School of Education, Department of Primary Education, University of Crete, Crete [in Greek].

Waldman, I. D., \& Gizer, I. R. (2006). The genetics of attention deficit hyperactivity disorder. Clinical Psychology Review, 26(4), 396-432.

Walker, H. M., Colvin, G., \& Ramsey, E. (1995). Antisocial behavior in school: Strategies and best practices. Pacific Grove, CA: Brooks/Cole.

Wheeler, E. (1994). Peer conflicts in the classroom: Drawing implications from research. Childhood Education, 70(5), $296-299$.

Wichstrom, L., Berg-Nielsen, T. S., Angold, A., Egger, H. L., Solheim, E., \& Sveen, T. H. (2011). Prevalence of psychiatric disorders in preschoolers. Journal of Child Psychology and Psychiatry, 53(6), 695-705.

Wilens, T. E., \& Fusillo, S. (2007). When ADHD and substance use disorders intersect: Relationship and treatment implications. Current Psychiatry Reports, 9(5), 408-414. 